Check for updates

Cite this: RSC Adv., 2018, 8, 37557

Received 30th August 2018

Accepted 1st November 2018

DOI: 10.1039/c8ra07238h

rsc.li/rsc-advances

\title{
An iodine/DMSO-catalyzed sequential one-pot approach to 2,4,5-trisubstituted-1H-imidazoles from $\alpha$-methylene ketones $\uparrow$
}

\author{
Janeeka Jayram (D) and Vineet Jeena (D)* \\ A sequential one-pot approach to 2,4,5-trisubstituted imidazoles has been developed from $\alpha$-methylene \\ ketones and aldehydes. This methodology employs air-moisture stable reaction conditions and an \\ inexpensive iodine/DMSO system affording a diverse range of known and novel (substrate scope) 2,4,5- \\ trisubstituted imidazoles in moderate to excellent yields. The iodine/DMSO system was extended to the \\ domino convergent synthesis of two functionalized intermediates, benzil and benzaldehyde, to produce \\ the final product.
}

\section{Introduction}

2,4,5-Trisubstituted imidazoles occupy a special place in the realm of natural, pharmaceutical and synthetic organic chemistry, as this moiety exhibits numerous biological and pharmacological properties. ${ }^{1}$ This particular $N$-heterocyclic family has expanded its applications in various fields such as cosmetics, ${ }^{2}$ polymer chemistry, ${ }^{3}$ agro chemicals, ${ }^{4}$ materials chemistry (OLEDS, optical electronics, dye sensitized solar cells), ${ }^{5}$ photography as photosensitive compounds ${ }^{6}$ and industry as a corrosion inhibitor of certain transition metals. ${ }^{7}$ Accordingly, synthetic routes to access 2,4,5-trisubstituted imidazoles are of vital importance and thus, develop on a daily basis.

The classical approach to assemble trisubstituted imidazoles involves the cyclocondensation of an $\alpha$-diketone, aldehyde and ammonium acetate using transition metal catalysts or acidic media (Scheme 1a). ${ }^{8}$ However, several of these transformations involve harsh reaction conditions, multistep synthetic operations, tedious isolation procedures and low yields. In particular, while synthetically useful, such methodologies are limited to accessibility of starting materials which in turn restrict product diversity. ${ }^{9}$

Recently, the selective oxidation of non-activated carbonhydrogen $(\mathrm{C}-\mathrm{H})$ bonds has become an area of profound interest in contemporary organic synthesis toward the formation of new carbon-carbon (C-C) and carbon-heteroatom $(\mathrm{C}-\mathrm{X}, \mathrm{X}=\mathrm{N}, \mathrm{O}, \mathrm{S}$, etc.) bonds. ${ }^{10}$ Specifically, the direct oxidation of unreactive benzylic $\mathrm{C}_{\mathrm{sp}^{3}}-\mathrm{H}$ bonds has received significant research interest to assemble $\mathrm{C}-\mathrm{N}$ bonds, since it represents an atom-economical

School of Chemistry and Physics, University of KwaZulu-Natal, Scottsville, Pietermaritzburg, 3209, South Africa.E-mail:Jeenav1@ukzn.ac.za

$\dagger$ Electronic supplementary information (ESI) available: Experimental details, characterization and copies of spectroscopic data. See DOI: 10.1039/c8ra07238h strategy. ${ }^{11}$ Within this context, numerous innovative systems for the oxidation of $\alpha$-methylene ketones to diketones have been reported such as $\mathrm{Cu}(\mathrm{OAc})_{2} / \mathrm{Ph}_{3} \mathrm{P},{ }^{12} \mathrm{Cu}(\mathrm{OAc})_{2} \cdot \mathrm{H}_{2} \mathrm{O} / \mathrm{K}_{2} \mathrm{CO}_{3},{ }^{13}$ $\mathrm{DMSO} / \mathrm{KHCO}_{3}$ (ref. 14) $\mathrm{KO}^{t} \mathrm{Bu} / 18$-Crown-6/O ${ }_{2},{ }^{15} \mathrm{Pd}(\mathrm{OAc})_{2} /$ triazole ligand $^{\mathbf{1 6}}$ and $\mathrm{CuO} / \mathrm{I}_{2} / \mathrm{DMSO} .^{17}$

Our research group has recently developed a new type of onepot domino process to synthesize 2,4,5-trisubstituted imidazoles through a $\mathrm{SeO}_{2} / \mathrm{HOAc}$ (Scheme 1b, Method 1) mediated oxidative cyclization from readily available $\alpha$-methylene ketones and aldehydes. ${ }^{18}$ However, the notable disadvantages of this protocol is the stoichiometric use of toxic selenium dioxide, selenium waste, acidic media and high reaction temperatures. Thus, in an effort to address the factors above, a copper $/ \mathrm{O}_{2}$ (Scheme 1b, Method 2) ${ }^{19}$ methodology was developed, however, while this approach proves its efficiency, the use of a transition

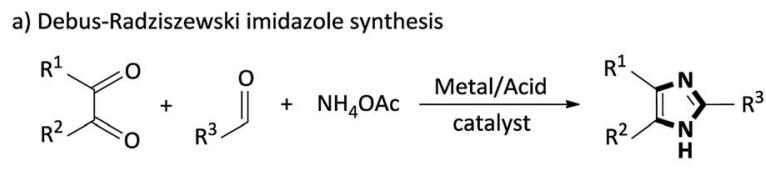

b) Previous work

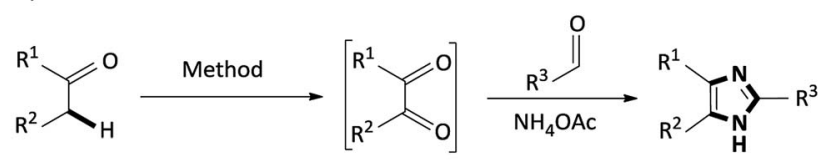

Method 1: $\mathrm{SeO}_{2} / \mathrm{HOAc}, 180^{\circ} \mathrm{C}$

Method 2: $\mathrm{Cu} / \mathrm{O}_{2}, 50^{\circ} \mathrm{C}$

c) This work (acid and transition metal-free imidazole synthesis)

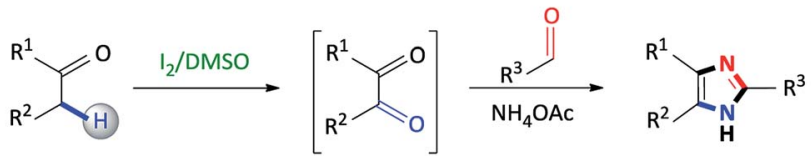

Scheme 1 Synthetic routes toward the preparation of 2,4,5-trisubstituted imidazoles. 
metal catalyst detracts from this synthetic procedure. As a result, there is scope for further improvements toward the development of non-toxic, acid and metal-free syntheses using simple, inexpensive reagents and convenient procedures, in which the above mentioned drawbacks can be addressed.

In this context, the concept of transition metal-free $\mathrm{C}-\mathrm{H}$ oxidation reactions is currently an active area of research and swiftly growing field in synthetic organic chemistry. ${ }^{20}$ Notably, in recent years, molecular iodine $\left(\mathrm{I}_{2}\right)$ has proven to be an excellent catalyst for various organic transformations owing to its inexpensive, non-toxic properties and mild Lewis acidity. ${ }^{21}$ Additionally, dimethylsulfoxide (DMSO) is an inexpensive and environmentally friendly polar aprotic compound that performs a versatile role as a solvent, oxidant and oxygen source in various organic syntheses. ${ }^{22}$ In recent times, the iodine/DMSO combination has received considerable attention, in synthetic organic chemistry, as an effective and eco-friendly oxidative system as it has effected numerous organic transformations. ${ }^{23}$

In continuation of our studies on nitrogen heterocyclic synthesis, ${ }^{24}$ we herein report an improved, non-toxic, acid and transition metal free, $\mathrm{I}_{2} / \mathrm{DMSO}$ promoted coupling of benzylic

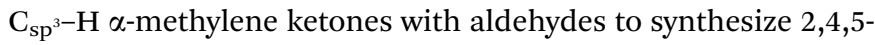
trisubstituted imidazoles (Scheme 1c).

\section{Experimental}

Typical procedure for the $I_{2} /$ DMSO-catalyzed reaction of $\alpha$ methylene ketones, aldehydes and ammonium acetate

2-Phenylacetophenone (196 mg, $1.0 \mathrm{mmol}$ ) and iodine (126 mg, $0.5 \mathrm{mmol}$ ) were mixed in a round bottomed flask with $1 \mathrm{~mL}$ DMSO and heated to $100{ }^{\circ} \mathrm{C}$ for 2 hours. Thereafter, benzaldehyde $(102 \mu \mathrm{L}, 1.0 \mathrm{mmol})$, ammonium acetate $(770 \mathrm{mg}, 10 \mathrm{mmol})$ and ethanol $(2 \mathrm{~mL})$ were sequentially added and the mixture heated to $100{ }^{\circ} \mathrm{C}$ for a further 2 hours. After cooling, a $\mathrm{Na}_{2} \mathrm{~S}_{2} \mathrm{O}_{3} /$ ice water solution was added to the reaction mixture to yield the crude product which was filtered, air dried and recrystallized from ethanol to afford the desired product.

The detailed characterization data for $\mathbf{3 a}-\mathbf{3} \mathbf{w}$ are provided in the ESI. $\dagger$

\section{Results and discussion}

Initially, our studies commenced using benzyl phenyl ketone 1a and benzaldehyde $2 \mathbf{a}$ as a model substrate and the results are presented in Table 1 . Firstly, 1a, 2a, ammonium acetate and $\mathbf{I}_{2}$ were added to DMSO and the mixture was heated at $100{ }^{\circ} \mathrm{C}$ for 4 hours, however, the reaction failed to proceed and no product was detected (Table 1, entry 1). Due to the failure of this reaction, we focused on sequential additions and accordingly, we attempted a reaction with 1a and $\mathrm{I}_{2}$ in DMSO, and heated at $100{ }^{\circ} \mathrm{C}$ for 2 hours, followed by the addition of $2 \mathrm{a}$ and ammonium acetate at $100{ }^{\circ} \mathrm{C}$ for a further 2 hours. Encouragingly, the expected 2,4,5-triphenylimidazole $3 a$ was obtained in an isolated yield of $54 \%$ (Table 1 , entry 2 ). Accordingly, we focused our studies on a sequential one-pot approach to prepare these scaffolds as this seemed to be the most viable synthetic route. In general, 2,4,5-trisubstituted imidazole syntheses proceed well
Table 1 Reaction optimization for the formation of 2,4,5triphenylimidazole ${ }^{a}$

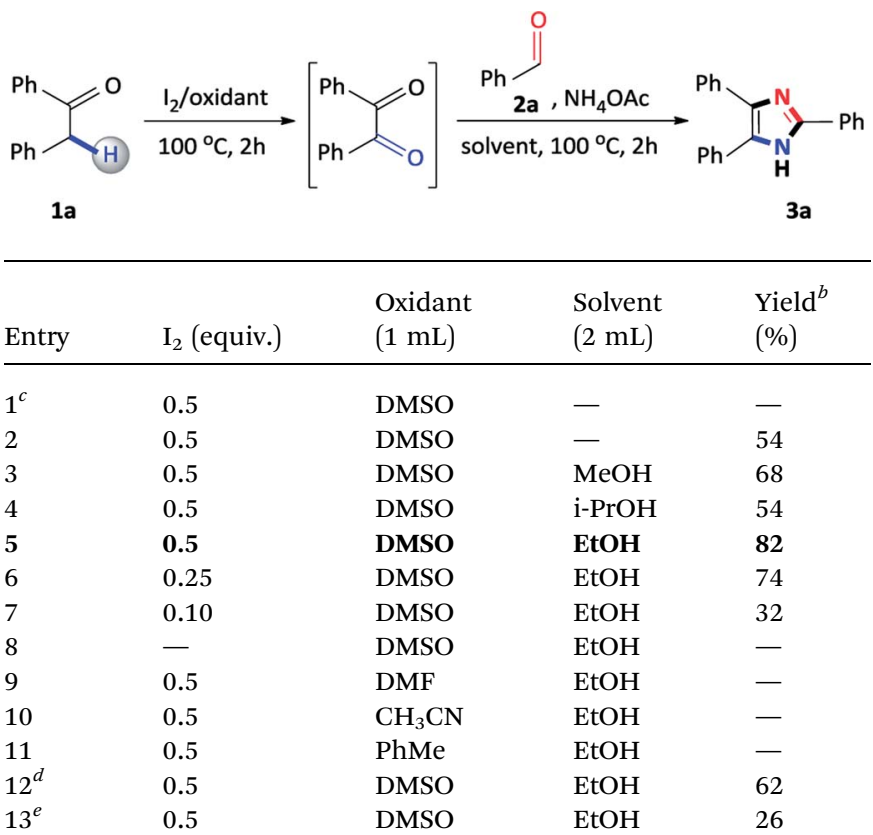

${ }^{a}$ Reaction conditions: Step I: $1 \mathrm{a}(1 \mathrm{mmol}), \mathrm{I}_{2}(0.5 \mathrm{mmol}), 100{ }^{\circ} \mathrm{C}$ for $2 \mathrm{~h}$; Step II: $2 \mathrm{a}(1 \mathrm{mmol}), \mathrm{NH}_{4} \mathrm{OAc}(10 \mathrm{mmol}), 100{ }^{\circ} \mathrm{C}$ for $2 \mathrm{~h} .{ }^{b}$ Isolated yield. ${ }^{c}$ One-pot reaction. ${ }^{d} \mathrm{NH}_{4} \mathrm{OAc}$ (5.0 equiv.). ${ }^{e} \mathrm{NH}_{4} \mathrm{OAc}$ (2.5 equiv.).

in the presence of an alcohol solvent as it is known to favour the coupling of a diketone, aldehyde and ammonium acetate. ${ }^{25}$ Thus, in order to improve the yield, the reaction was attempted with methanol and iso-propanol affording $3 \mathrm{a}$ in $68 \%$ and $54 \%$ yield respectively (Table 1, entries 3 and 4). Finally, ethanol was shown to be the best performing additive solvent as the yield significantly increased to $82 \%$ (Table 1 , entry 5). Attempts were made to decrease the amount of iodine, however, 0.25 and 0.10 equivalents lowered the yield of the desired product to $74 \%$ and $32 \%$ respectively (Table 1, entries 6 and 7). Furthermore, performing the reaction in the absence of iodine resulted in no product formation thus, confirming its importance in this multicomponent reaction (Table 1 , entry 8 ). The reaction also failed to produce the expected 2,4,5-triphenylimidazole 3a when DMSO was replaced with alternative oxidants such as dimethylformamide (DMF), acetonitrile $\left(\mathrm{CH}_{3} \mathrm{CN}\right)$ and toluene (PhMe) confirming its vital importance in the reaction (Table 1, entries 9-11). Many synthetic procedures use varying amounts of ammonium acetate depending on the reaction conditions employed to produce the desired product in maximum yield. ${ }^{26}$ Thus, to complete the study, the amount of ammonium acetate was reduced to 5.0 and 2.5 equivalents, however, the yield of $\mathbf{3 a}$ considerably decreased to $62 \%$ and $26 \%$ (Table 1 , entries 12 and 13). To conclude, the conditions described in entry 5 were found to be optimal, allowing for maximum conversion to the desired product 3a.

Having identified the optimized reaction conditions, the applicability of the devised system was evaluated by varying the $\alpha$-methylene ketone and aldehyde (Scheme 2). The various 
electron-withdrawing and electron-donating para-substituted benzaldehydes all underwent a smooth transformation with 1a to provide the corresponding 2,4,5-trisubstituted imidazoles 3b-3d in good to excellent yields (80-86\%). Similar results were obtained upon substitution at the meta and ortho position of benzaldehyde producing good yields of 63-75\% (Schemes 2 and $3 \mathbf{e}-\mathbf{3 g}$ ). In order to expand the scope of our methodology, a bulkier substrate, 2-naphthaldehyde was evaluated and also coupled smoothly with 1a to afford 2-(naphthalene-2-yl)-4,5diphenyl- $1 H$-imidazole $3 \mathbf{h}$ in a $74 \%$ yield. We further extended our methodology to heterocyclic and aliphatic aldehydes such as furfural, cyclohexanecarboxaldehyde and 2-ethylbutyraldehyde to produce the desired imidazoles $3 \mathbf{i}-\mathbf{3 k}$ albeit, in moderate yields with prolonged reaction time. Next, reactions of benzaldehyde with substituted $\alpha$-methylene ketones were investigated. Unfortunately, propiophenone and 2-butanone were not compatible with this system, and only starting material was recovered. Benzyl phenyl ketone 1a substituted with para-Cl or Br-groups reacted smoothly to furnish 2,4,5-trisubstituted imidazoles $3 \mathbf{n}-\mathbf{3 o}$ in good to excellent yields (78-84\%).
Similarly, coupling 4-chloro-2-phenylacetophenone with para substituted benzaldehydes, under the optimized reaction conditions, successfully afforded the corresponding heterocyclic imidazoles 3p-3r in good yields (66-76\%). Compounds 3n$3 \mathbf{r}$ were isolated as a mixture of tautomers due to the presence of the fluid hydrogen on the nitrogen atom.

Recently, several 2,4,5-trisubstituted imidazoles were shown to have activity against malarial strains owing to the novelty of the chemotype. ${ }^{27}$ As a result, in order to enhance the diversity and thus the possible biological relevance of the imidazole scaffold, we decided to establish substrate scope with this strategy which is not known in literature. As a result, a series of novel 2,4,5-trisubstituted imidazoles $3 \mathbf{r}-\mathbf{3} \mathbf{w}$ were synthesized as a mixture of tautomers in good to excellent yields (53-85\%) (Scheme 3). Consequently, this atom-economical synthetic procedure overcomes the limitations of previous methodologies which are restricted to the accessibility of starting materials, thus creating a new avenue to synthesize numerous novel imidazole derivatives yielding drug like properties. Next, we turned our attention to the domino convergent synthesis of two

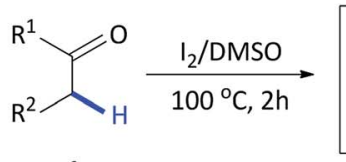

1

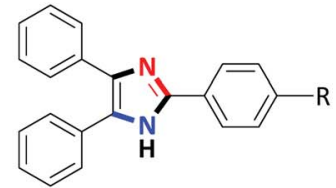

3a, $\mathrm{R}=\mathrm{H}, 82 \%$

3b, $\mathrm{R}=\mathrm{Cl}, 86 \%$

3c, $\mathrm{R}=\mathrm{Br}, 82 \%$

3d, $R=M e, 80 \%$

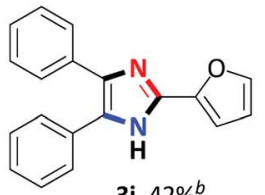

3i, $42 \%^{b}$

$3 n, 84 \%$

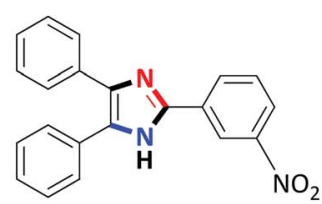

3e, $75 \%$

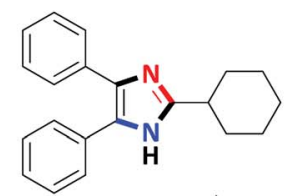

3j, $51 \%^{b}$

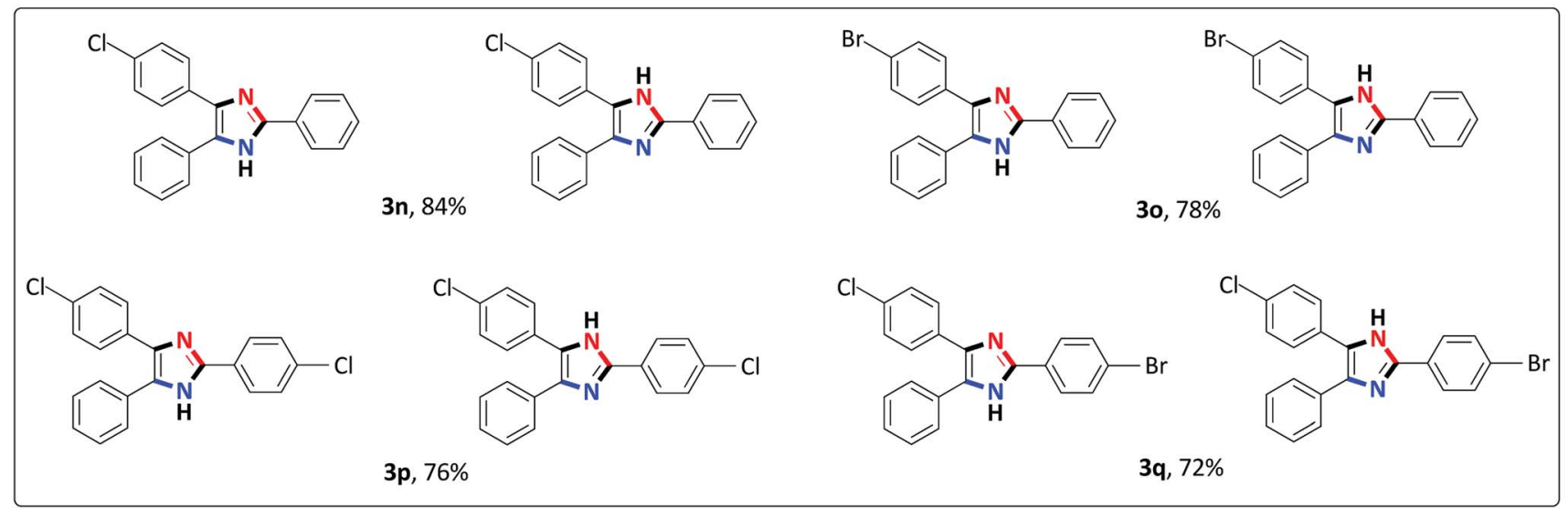

$+\mathrm{R}^{3} \stackrel{\mathrm{O}}{\stackrel{\mathrm{NH}_{4} \mathrm{OAc}}{\mathrm{EtOH}, 100^{\circ} \mathrm{C}, 2 \mathrm{~h}}}$

2

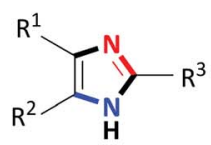

$3^{a}$

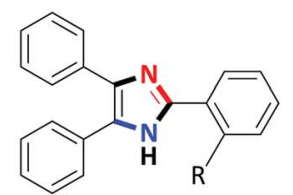

3f, $R=$ OMe, $63 \%$

$3 g, R=F, 68 \%$

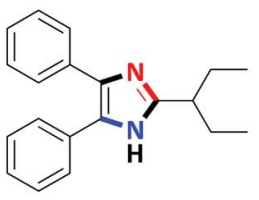

3k, $35 \%^{b}$

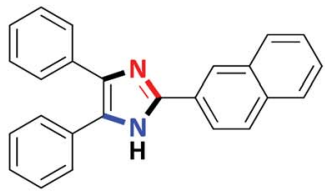

3h, $74 \%$

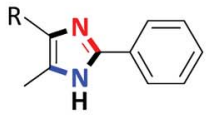

3I, $\mathrm{R}=\mathrm{Ph}, 0 \%^{\mathrm{c}}$

$3 \mathrm{~m}, \mathrm{R}=\mathrm{Me}, 0 \%^{\mathrm{c}}$

Scheme 2 Step I: $1(1 \mathrm{mmol}), \mathrm{I}_{2}(0.5 \mathrm{mmol}), \mathrm{DMSO}(1 \mathrm{~mL}), 100{ }^{\circ} \mathrm{C}$ for $2 \mathrm{~h}$; Step II: $2(1 \mathrm{mmol}), \mathrm{NH}_{4} \mathrm{OAc}(10 \mathrm{mmol}), \mathrm{EtOH}(2 \mathrm{~mL}), 100{ }^{\circ} \mathrm{C}$ for $2 \mathrm{~h}$. ${ }^{a}$ Isolated yield. ${ }^{b}$ Step II: 24 h. ${ }^{c}$ Step I: $24 \mathrm{~h}$. 

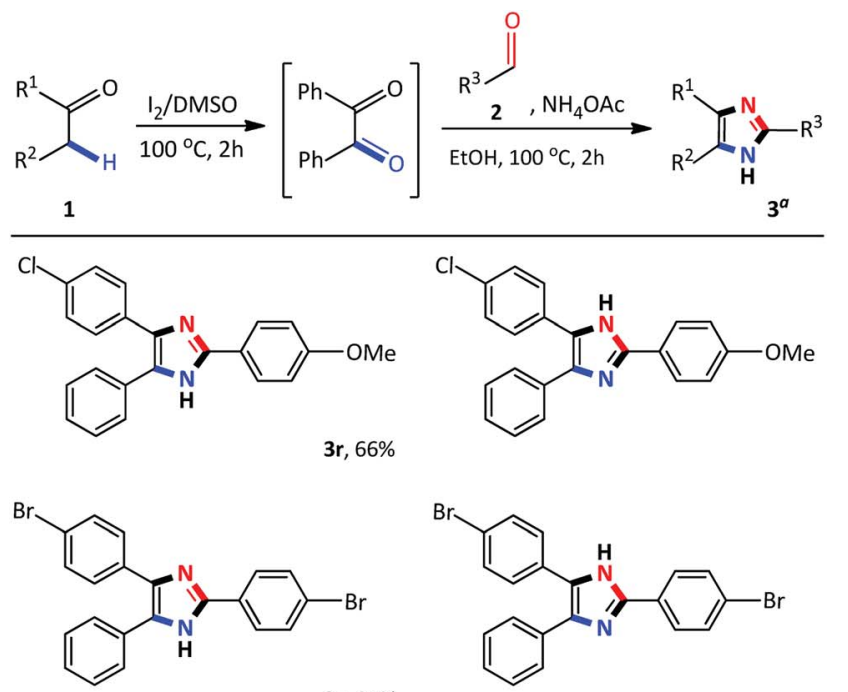

$3 s, 81 \%$

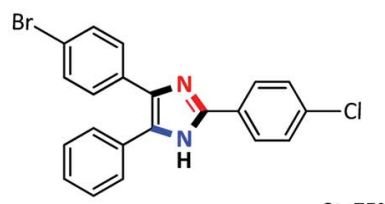

3t, $75 \%$

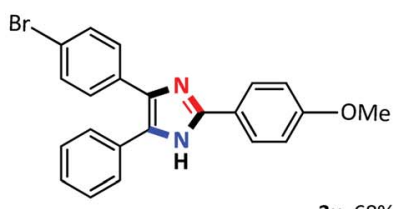

$3 u, 68 \%$

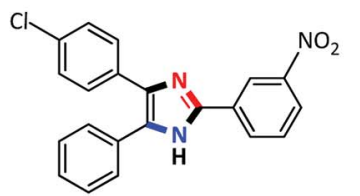

$3 v, 85 \%$

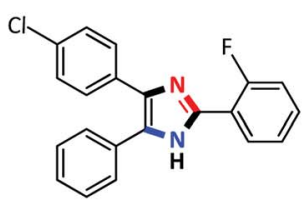

$3 w, 53 \%$
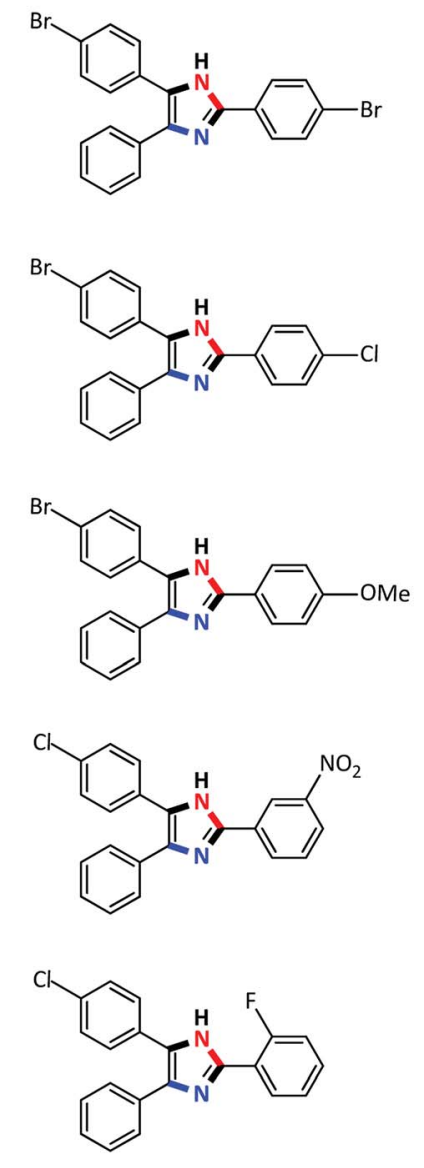

Scheme 3 Synthesis of novel 2,4,5-trisubstituted imidazoles. Step I: 1 $(1 \mathrm{mmol}), \mathrm{I}_{2}(0.5 \mathrm{mmol}), \mathrm{DMSO}(1 \mathrm{~mL}), 100{ }^{\circ} \mathrm{C}$ for $2 \mathrm{~h}$; Step II: 2 (1 $\mathrm{mmol}), \mathrm{NH}_{4} \mathrm{OAc}(10 \mathrm{mmol}), \mathrm{EtOH}(2 \mathrm{~mL}), 100^{\circ} \mathrm{C}$ for $2 \mathrm{~h} .{ }^{a}$ Isolated yield.

suitably functionalized intermediates, benzil and benzaldehyde, to converge onto the final product 3a. As previously mentioned, the $\mathrm{I}_{2} /$ DMSO system is able to effect numerous organic transformations, hence, we rationalized that this system could simultaneously oxidize the benzyl phenyl ketone 1a and benzyl alcohol $4 \mathbf{a}$, in the same reaction vessel, to produce the diketone and aldehyde which will subsequently form the desired imidazole using our devised system. To test this hypothesis we mixed benzyl phenyl ketone 1a and benzyl alcohol $4 a$ in the presence of $\mathrm{I}_{2} / \mathrm{DMSO}$ and heated the mixture at $100{ }^{\circ} \mathrm{C}$ for 24 hours to form the corresponding diketone and aldehyde. Thereafter, ammonium acetate and ethanol were

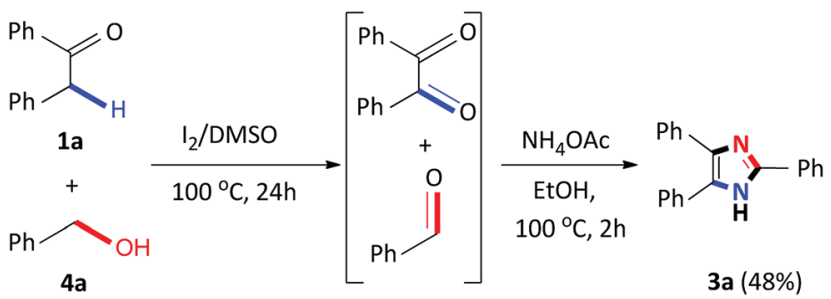

Scheme 4 Domino convergent synthesis of 2,4,5-triphenyl imidazole $3 a$.

added to the reaction and heated at $100{ }^{\circ} \mathrm{C}$ for a further 2 hours to afford 3a in an isolated yield of $48 \%$ (Scheme 4). This result illustrates that the $\mathrm{I}_{2}$ /DMSO system can successfully oxidize two different substrates simultaneously, in the same reaction vessel, for convergent synthesis into the desired product. We further anticipate that this result would inspire the design for more efficient and eco-friendly domino convergent syntheses for the preparation of complex products from simple materials via this innovative synthetic strategy.

To investigate a plausible reaction mechanism, a series of control experiments were performed (Scheme 5). In experiment 1 , benzyl phenyl ketone 1a was oxidized, in the presence of $I_{2} /$ DMSO to benzil 5a (96\%) which indicates that the diketone is an intermediate in the reaction. Under the iodine-catalysis conditions, the addition of the radical inhibitor (2,2,6,6tetramethylpiperidin-1-yl)oxyl (TEMPO) afforded the capture adduct 6a in $46 \%$ (experiment 2). The TEMPO-trapped reaction strongly supports the formation of $\mathbf{6 a}$, in which the radical is located at the $\alpha$-position of benzyl phenyl ketone. In order to rule out the role of hydroxyl and peroxide radicals as an intermediate, a reaction of benzyl phenyl ketone 1a with butylated hydroxytoluene $(\mathrm{BHT})^{28}$ in the presence of $\mathrm{I}_{2}$ in DMSO was performed (experiment 3). In this reaction, the diketone was obtained in $90 \%$ yield, thereby proving non participation of peroxide radicals in our reaction. Mechanistically, we proposed that an $\alpha$-iodinated species is the reactive intermediate in the oxidation of 1a to afford the benzil intermediate 5a. Accordingly, 2-iodo-1,2-diphenylethanone $7 \mathrm{a}$ was synthesized ${ }^{29}$ and subject to oxidation in DMSO affording benzil in $97 \%$ yield (experiment 4). Having completed the iodination reaction, we sought to determine the source of oxygen in the oxidation reaction. Accordingly, there are three potential oxygen sources in the reaction system: molecular oxygen in air, a trace amount of water in the solvent DMSO and, DMSO itself. The reaction proceeded well under a nitrogen atmosphere affording $\mathbf{5 a}$ in $95 \%$ yield indicating that oxygen from the air does not participate in the reaction (experiment 5). When the reaction was performed in a toluene/water biphasic mixture, the hydroxylation product $\mathbf{8} \mathbf{a}$ and benzil intermediate $\mathbf{5 a}$ was obtained in $22 \%$ and $16 \%$ yield respectively, indicating that water plays a minor role in the oxidation reaction to afford 8a which is further oxidized to provide 5a (experiment 6). Furthermore, the reaction of $7 \mathbf{a}$ in anhydrous DMSO under a nitrogen atmosphere afforded the diketone intermediate in $98 \%$ yield (experiment $6 \mathrm{~b}$ ). This preliminary result confirms that majority of the incorporated oxygen in the benzil intermediate is indeed 
<smiles>CCCCCCC(=O)C(=O)c1ccccc1</smiles>

1a $\frac{\mathrm{I}_{2} / \mathrm{DMSO}, 1 \text { equiv. TEMPO }}{100^{\circ} \mathrm{C}, 2 \mathrm{~h}}$<smiles>CC1(C)CCCC(C)(C)N1OC(C(=O)c1ccccc1)c1ccccc1</smiles>

6a $(46 \%)$

$1 a$

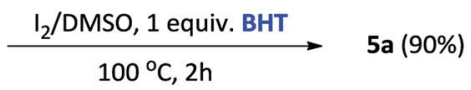

(3)<smiles>O=C(c1ccccc1)C(I)c1ccccc1</smiles>
DMSO, $100^{\circ} \mathrm{C}, 2 \mathrm{~h}$ 7a

1a

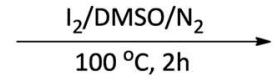

5a $(95 \%)$

(5)

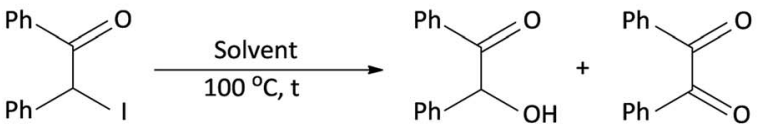

$7 a$

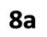

$5 a$

Solvent: $\mathrm{PhMe} / \mathrm{H}_{2} \mathrm{O}(1: 1), 1 \mathrm{~h}$ anhydrous DMSO/N $/ 2 \mathrm{~h}$ )

$22 \%$

n. d.

$16 \%$

$98 \%$

(a)

(b)

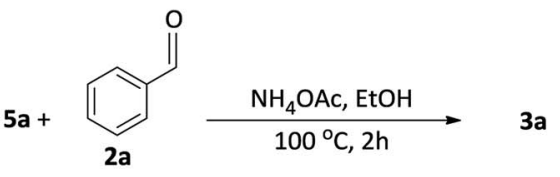
a) $\mathrm{NoI}_{2}$
N. R.
b) $\mathrm{I}_{2}$
$92 \%$

Scheme 5 Control experiments.

coming from DMSO. Finally, in order to understand the effect of iodine in the coupling reaction, $\mathbf{1 a}, \mathbf{2 a}$ and ammonium acetate was reacted in ethanol to afford the corresponding 2,4,5-triphenylimidazole 3a, however, no product was obtained (experiment 7a). Moreover, the addition of iodine resulted in $92 \%$ formation of $\mathbf{3 a}$ indicating that iodine plays a role in the coupling reaction (experiment $7 \mathrm{~b}$ ). On the basis of the above observations, we propose a plausible mechanism of consecutive iodination/oxidation/cyclization for the synthesis of 2,4,5trisubstituted imidazoles (Scheme 6). The reaction proceeds

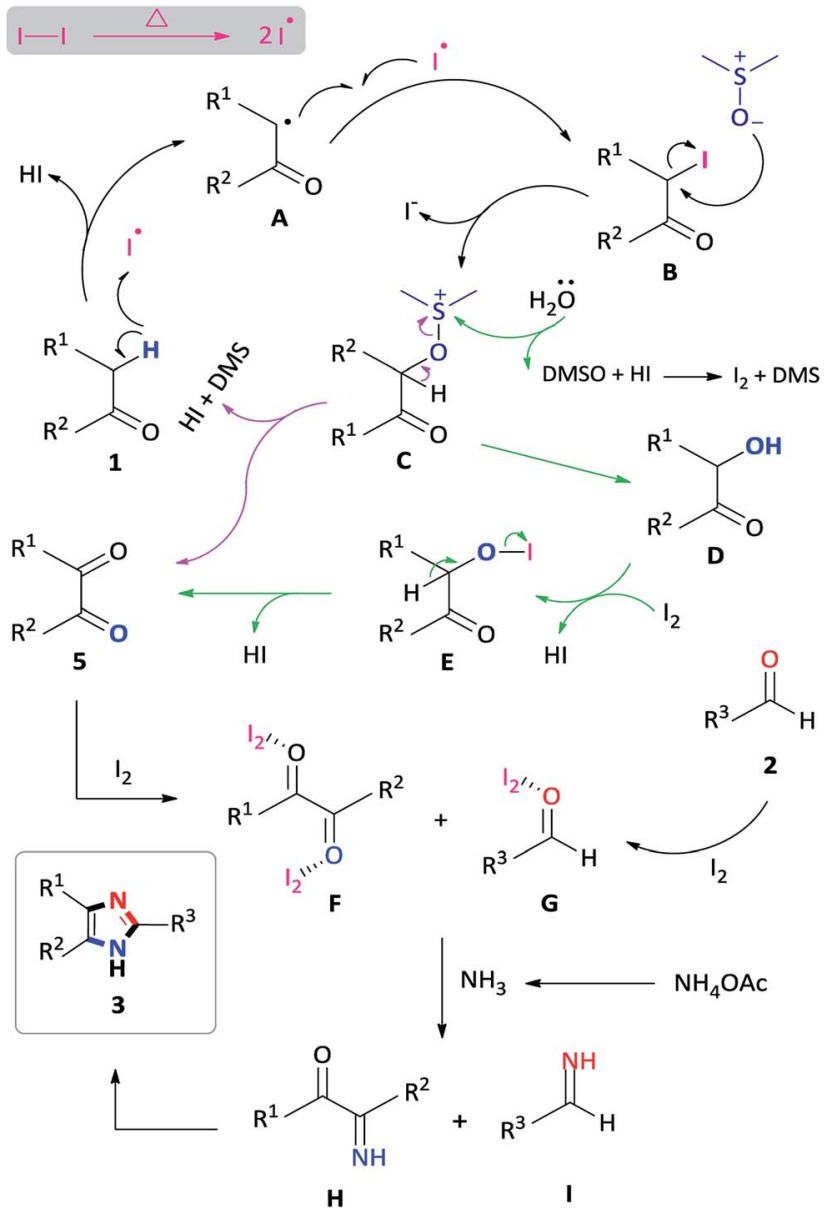

Scheme 6 Plausible mechanism for imidazole synthesis.

with an iodine assisted proton abstraction from the methylene position of 1 to generate the benzyl radical A. ${ }^{30}$ Subsequently, iodination affords the corresponding $\alpha$-iodinated intermediate, 2-iodo-1,2-diphenylethanone $\mathbf{B}$, which reacts with DMSO to generate the active intermediate $\mathbf{C}$. Two possible pathways could be proposed for the reaction of $\mathbf{C}$ to form the benzil intermediate $5 .^{31}$ Based on control experiment 6 , the minor pathway (green) involves a water attack on the sulfur cation of $\mathbf{C}$ to form the hydroxylation intermediate $\mathbf{D}$, regenerating DMSO and $\mathrm{HI}$ for further cycle, which subsequently forms 5 through intermediate $\mathbf{E} .^{32}$ On the other hand, the major pathway (purple) involves proton abstraction from the $\alpha$-carbon of $\mathbf{C}$, followed by the removal of $\mathrm{HI}$ and DMS, affording the desired benzil intermediate 5. Accordingly, the oxidation of $\mathbf{B}$ is not solely a DMSO catalyzed reaction, since the catalytic water still exists, but majorly relies on the DMSO to react with the $\alpha$-iodinated intermediate to afford the diketone intermediate 5. In terms of the coupling reaction, ${ }^{33}$ iodine is capable of binding to the carbonyl oxygen of the diketone intermediate $\mathbf{5}$ and aldehyde $\mathbf{2}$, owing to its mild Lewis acidity, thus increasing the reactivity of the substrates, ${ }^{34}$ which is supported by control experiment $7 \mathrm{~b}$. Moreover, iodine facilitates the formation of the imine intermediates $\mathbf{H}$ and $\mathbf{I}$ which condense to form the desired imidazole 3 . 


\section{Conclusion}

In summary, an improved, non-toxic, acid and transition metal free, sequential one-pot approach to 2,4,5-trisubstituted imidazoles was developed using $\alpha$-methylene ketones instead of the traditional diketone. This environmentally friendly $\mathrm{I}_{2} / \mathrm{DMSO}$ system provides access to various substituted 2,4,5-trisubstituted imidazoles in moderate to excellent yields, under mild conditions and short reaction times. Moreover, a substrate scope was established by synthesizing novel 2,4,5-trisubstituted imidazoles, in good to excellent yields, which could potentially have biological properties. In addition, this approach could effect a domino convergent synthesis of the desired imidazole albeit in a moderate yield, through the simultaneous oxidation of benzyl phenyl ketone and benzyl alcohol. Supplementary studies expanding the scope of this methodology as well as indepth mechanistic experiments are currently underway in our laboratories and will be reported in due course.

\section{Conflicts of interest}

There are no conflicts to declare.

\section{Acknowledgements}

We are grateful to the National Research Foundation (NRF) of South Africa for a postgraduate bursary (JJ) and a Thuthuka research grant (VJ).

\section{Notes and references}

1 (a) M. Roue, I. Domart-Coulon, A. Ereskovsky, C. Djediat, T. Perez and M. L. BourguetKondracki, J. Nat. Prod., 2010, 73, 1277-1282; (b) L. Zhang, X. M. Peng, G. L. Damu, R. X. Geng and C. H. Zhou, Med. Res. Rev., 2014, 34, 340437; (c) B. Cui, B. L. Zheng, K. He and Q. Y. Zheng, J. Nat. Prod., 2003, 66, 1101-1103; (d) S. Tsukamoto, T. Kawabata, H. Kato, T. Ohta, H. Rotinsulu, R. E. P. Mangindaan, R. W. M. Van Soest, K. Ukai, H. Kobayashi and M. Namikoshi, J. Nat. Prod., 2007, 70, 1658-1660; (e) Z. Jin, Nat. Prod. Rep., 2009, 26, 382-445; (f) S. Baroniya, Z. Anwer, P. K. Sharma, R. Dudhe and N. Kumar, Der Pharmacia Sinica, 2010, 1, 172-182; (g) I. Ali, M. N. Lone and H. Y. Aboul-Enein, Med. Chem. Commun., 2017, 8, 1742-1773.

2 (a) M. A. Babizhayev, Life Sci., 2006, 78, 2343-2357; (b) M. A. Babizhayev, G. M. Nikolayev, J. G. Nikolayeva and Y. E. Yegorov, Am. J. Ther., 2012, 19, 69-89.

3 (a) W. Wang, X. Ji, A. Kapur, C. Zhang and H. Mattoussi, J. Am. Chem. Soc., 2015, 137, 14158-14172; (b) J. V. Olsson, D. Hult, Y. Cai, S. Garcia-Gallego and M. Malkoch, Polym. Chem., 2014, 5, 6651-6655.

4 (a) L. Chen, B. Zhao, Z. Fan, X. Liu, Q. Wu, H. Li and H. Wang, J. Agric. Food Chem., 2018, 66, 7319-7327; (b) J.-H. Choi, N. Abe, A. Tanaka, K. Fushimi, Y. Nishina, A. Morita, Y. Kiriiwa, R. Motohashi, D. Hashizume, H. Koshino and H. Kawagishi, J. Agric. Food Chem., 2010, 158, 9956-9959.
5 (a) P. Abhishek, C. J. Kulkarni, A. B. Tonzola and A. J. Samson, Chem. Mater., 2004, 16, 4556-4573; (b) Z. Wang, P. Lu, S. Chen, Z. Gao, F. Shen, W. Zhang, Y. Xu, H. S Kwok and Y. Ma, J. Mater. Chem., 2011, 21, 5451-5456; (c) K. Takagi, K. Kusafuka, Y. Ito, K. Yamauchi, K. Ito, R. Fukuda and M. Ehara, J. Org. Chem., 2015, 80, 71727183; (d) D. Kumar, K. R. J. Thomas, C.-P. Lee and K.-C. Ho, J. Org. Chem., 2014, 79, 3159-3172; (e) X. Chen, C. Jia, Z. Wan and X. Yao, Dyes Pigm., 2014, 104, 48-56.

6 (a) H. Yamashita and J. Abe, J. Phys. Chem. A, 2011, 115, 13332-13337; (b) K. Motoh and J. Abe, J. Phys. Chem. A, 2011, 115, 4650-4656.

7 (a) L. Zhang, Y. He, Y. Zhou, R. Yang, Q. yang, D. Qing and Q. Niu, Petroleum, 2015, 1, 237-243; (b) M. M. Antonijevic and M. B. Petrovic, Int. J. Electrochem. Sci., 2008, 1, 1-28.

8 Selected recent examples include: $(a)$ A. Bamoniri, B. F. Mirjalili, S. Nazemian and N. Y. Mahabadi, Bulg. Chem. Commun., 2014, 46, 79-84; (b) A. Maleki, H. Movahed and R. Paydar, RSC Adv., 2016, 6, 1365713665; (c) A. Teimouri and A. N. Chermahini, J. Mol. Catal. A: Chem., 2011, 346, 39-45; (d) B. Sadeghi, B. B. F. Mirjalili and M. M. Hashemi, Tetrahedron Lett., 2008, 49, 25752577; (e) A. R. Karimi, Z. Alimohammadi and M. M. Amini, Mol. Diversity, 2010, 14, 635-641; $(f)$ R. H. Shoar, G. Rahimzadeh, F. Derikvand and M. Farzaneh, Synth. Commun., 2010, 40, 1270-1275; (g) S. A. Dake, M. B. Khedkar, G. S. Irmale, S. J. Ukalgaonkar, V. V. Thorat, S. A. Shintre and R. P. Pawar, Synth. Commun., 2012, 42, 1509-1520; (h) H. R. Shaterian and M. Ranjbar, J. Mol. Liq., 2011, 160, 40-49.

9 (a) D. Yang, D. Fokas, J. Li, L. Yu and C. M. Baldino, Synthesis, 2005, 47-56; (b) K. Bahrami, M. M. Khodaei and F. Naali, J. Org. Chem., 2008, 73, 6835-6837; (c) L. J. Goossen and T. Knauber, J. Org. Chem., 2008, 73, 8631-8634.

10 (a) Y. Ashikari, T. Nokami and J.-I. Yoshida, J. Am. Chem. Soc., 2011, 133, 11840-11843; (b) Y. Ashikari, T. Nokami and J.-I. Yoshida, Org. Lett., 2012, 14, 938-941; (c) A. E. Wendlandt, A. M. Suess and S. S. Stahl, Angew. Chem., Int. Ed., 2011, 50, 11062-11087; For selected recent reviews see:(d) T. Punniyamurthy, S. Velusamy and J. Iqbal, Chem. Rev., 2005, 105, 2329-2364; (e) Z. Shi, C. Zhang, C. Tang and N. Jiao, Chem. Soc. Rev., 2012, 41, 3381-3430; $(f)$ J. Mlochowski and H. Wójtowicz-Mlochowski, Molecules, 2015, 20, 10205-10243.

11 (a) J. Xie, C. Pan, A. Abdukader and C. Zhu, Chem. Soc. Rev., 2014, 43, 5245-5256; (b) M. L. Louillat and F. W. Patureau, Chem. Soc. Rev., 2014, 43, 901-910; (c) K. Wu, Z. Huang, X. Qi, Y. Li, G. Zhang, C. Liu, H. Yi, L. Meng, E. E. Bunel, J. T. Miller, C.-W. Pao, J.-F. Lee, Y. Lan and A. Lei, Sci. Adv., 2015, 1, e1500656; (d) S. Guo, Q. Zhang, H. Li, H. Guo and W. He, Nano Res., 2017, 10, 3261-3267; (e) W. Shi, C. Liu and A. Lei, Chem. Soc. Rev., 2011, 40, 2761-2776.

12 S. Cacchi, G. Fabrizi, A. Goggiamani, A. Lazzetti and R. Verdiglione, Synthesis, 2013, 45, 1701-1707.

13 J.-W. Yu, S. Mao and Y.-Q. Wang, Tetrahedron Lett., 2015, 56, 1575-1580. 
14 R. Chebolu, A. Bahuguna, R. Sharma, V. K. Mishra and P. C. Ravikumar, Chem. Commun., 2015, 51, 15438-15441.

15 H. Wang, Z. Wang, H. Huang, J. Tan and K. Xu, Org. Lett., 2016, 18, 5680-5683.

16 G. Urgoitia, A. Maiztegi, R. SanMartin, M. T. Herrero and E. Dominguez, RSC Adv., 2015, 5, 103210-103217.

17 M. Lian, Q. Li, Y. Zhu, G. Yin and A. Wu, Tetrahedron, 2012, 68, 9598-9605.

18 V. Jeena and M. Mazibuko, Heterocycles, 2017, 94, 19091922.

19 J. Jayram and V. Jeena, Green Chem., 2017, 19, 5841-5845.

20 (a) R. Zhou, H. Liu, H. Tao, X. Yu and J. Wu, Chem. Sci., 2017, 8, 4654-4659; (b) U. K. Das, L. J. W. Shimon and D. Milstein, Chem. Commun., 2017, 53, 13133-13136; (c) Y. Z. Yan, Y. H. Zhang, C. T. Feng, Z. G. Zha and Z. Y. Wang, Angew. Chem., Int. Ed., 2012, 51, 8077-8081; (d) Y. P. Zhu, Z. Fei, M. C. Liu, F. C. Jia and A. X. Wu, Org. Lett., 2013, 15, 378381; (e) Y. Z. Yan, Y. Xu, B. Niu, H. F. Xie and Y. Q. Liu, J. Org. Chem., 2015, 80, 5581-5587; (f) C. Mukhopadhyay and P. K. Tapaswi, Green Chem. Lett. Rev., 2015, 5, 109-120.

21 (a) Y.-D. Wu, X. Geng, Q. Gao, J. Zhang, X. Wu and A.-X. Wu, Org. Chem. Front., 2016, 3, 1430-1434; (b) K. K. D. R. Viswanadham, M. P. Reddy, P. Sathyanarayana, O. Ravi, R. Kant and S. R. Bathula, Chem. Commun., 2014, 50, 13517-13520; (c) C. Chen, C. Chen, B. Li, J. Tao and J. Peng, Molecules, 2012, 17, 12506-12520; (d) B. P. Bandgar, S. V. Bettigeri and N. S. Joshi, Synth. Commun., 2004, 34, 1447-1453; (e) X. Yi, L. Jiao and C. Xi, Org. Biomol. Chem., 2016, 14, 9912-9918.

22 (a) S. Song, X. Huang, Y. -F. Liang, C. Tang, X. Li and N. Jiao, Green Chem., 2015, 17, 2727-2731; (b) J.-C. Xiang, Q.-H. Gao and A.-X. Wu, in Solvents as reagents in organic synthesis: reactions and applications, ed. X.-F. Wu, Wiley-VCH Verlag GmbH \& Co., Germany, 2017, ch. 7, pp. 315-349.

23 For selected recent review see: A. Monga, S. Bagchi and A. Sharma, New J. Chem., 2018, 52, 1551-1576.

24 (a) J. Jayram and V. Jeena, Heterocycles, 2016, 92, 2213-2224; (b) S. Naidoo and V. Jeena, Heterocycles, 2016, 92, 1655-1664. 25 (a) G. A. Price, A. K. Brisdon, K. R. Flower, R. G. Pritchard and P. Quayle, Tetrahedron Lett., 2014, 55, 151-154; (b) D. S. MacMillan, J. Murray, H. F. Sneddon, C. Jamieson and A. J. B. Watson, Green Chem., 2013, 15, 596-600; (c) M. Kidwai, P. Mothsra, V. Bansal and R. Goyal, Monatshefte für Chemie, 2006, 137, 1189-1194.

26 (a) S. Balalaie and A. Arabanian, Green Chem., 2000, 2, 274276; (b) Y. Xu, L. F. Wan, H. Salehi, W. Deng and X. Qing, Heterocycles, 2004, 63, 1613-1618; (c) A. Parveen, A. Ahmed and S. K. Ahmed, Res. J. Pharm., Biol. Chem. Sci., 2010, 1,
943-951; (d) E. Chauveau, C. Marestin, F. Schiets and R. Mercier, Green Chem., 2010, 12, 1018-1022; (e) M. Esmaeilpour, J. Javidi and M. Zandi, New J. Chem., 2015, 39, 3388-3398; (f) Z. Zarnegar and J. Safari, New J. Chem., 2014, 38, 4555-4565; (g) J. Safari and Z. Zarnegar, Ultrason. Sonochem., 2013, 20, 740-746.

27 (a) K. J. Wicht, J. M. Combrinck, P. J. Smith, R. Hunter and T. J. Egan, ACS Med. Chem. Lett., 2017, 8, 201-205; (b) F.-j. Gamo, L. M. Sanz, J. Vidal, C. de Cozar, E. Alvarez, J. L. Lavandera, D. E. Vanderwall, D. V. S. Green, V. Kumar, S. Hasan, J. R. Brown, C. E. Peishoff, L. R. Cardon and J. F. Garcia-Bustos, Nature, 2010, 465, 305-312; (c) K. Y. Fong, R. D. Sandlin and D. W. Wright, Int. J. Parasitol.: Drugs Drug Resist., 2015, 5, 84-91; (d) D. Plouffe, A. Brinker, C. McNamara, K. Henson, N. Kato, K. Kuhen, A. Nagle, F. Adrian, J. T. Matzen, P. Anderson, T.-g. Nam, N. S. Gray, A. Chatterjee, J. Janes, S. F. Yan, R. Trager, J. S. Caldwell, P. G. Schultz, Y. Zhou and E. A. Winzeler, Proc. Natl. Acad. Sci. U. S. A., 2008, 105, 9059-9064.

28 (a) C. R. Lambert, H. S. Black and T. G. Truscott, Free Radical Biol. Med., 1996, 21, 395-400; (b) H. S. Black, Front. Biosci., 2002, 7, 1044-1055.

29 V. Estevez, M. Villacampa and J. C. Menendez, Chem. Commun., 2013, 49, 591-593.

30 (a) J. Gromada and K. Matyjaszewski, Macromolecules, 2001, 34, 7664-7671; (b) H.-Y. Huang, H.-R. Wu, F. Wei, D. Wang and L. Liu, Org. Lett., 2015, 17, 3702-3705.

31 (a) H.-L. Li, X.-L. An, L.-S. Ge, X. Luo and W.-P. Deng, Tetrahedron, 2015, 71, 3247-3252; (b) Y. Liang, K. Wu, S. Song, X. Li, X. Huang and N. Jiao, Org. Lett., 2015, 17, 876-879.

32 (a) D. von de Heiden, S. Bozkus, M. Klussmann and M. Breugst, J. Org. Chem., 2017, 82, 4037-4043; (b) C. Xie, Z. Zhang, B. Yang, G. Song, H. Gao, L. Wen and C. Ma, Tetrahedron, 2015, 71, 1831-1837.

33 S. S. K. Boominathan, C.-Y. Chen, P.-J. Huang, R.-J. Hou and J.-J. Wang, New J. Chem., 2015, 39, 6914-6918.

34 (a) M. Kidwai, P. Mothsra, V. Bansal, R. K. Somvanshi, A. S. Ethayathulla, S. Dey and T. P. Singh, J. Mol. Catal. A: Chem., 2007, 265, 177-182; (b) S. S. Ali, Arch. Appl. Sci. Res., 2010, 2, 392-397; (c) L. Wu, B. Niu, W. Li and F. Yan, Bull. Korean Chem. Soc., 2009, 30, 2777-2778; (d) S. Patil, J. Patil and S. Dharap, WJPR, 2015, 4, 2476-2483; (e) H. P. Kalmode, K. S. Vadagaonkar and A. C. Chaskar, RSC $A d v ., \quad 2014, \quad 4$, 60316-60326; (f) H. P. Kalmode, K. S. Vadagaonkar and A. C. Chaskar, Synthesis, 2015, 47, 429-438; (g) R. Deshidi, M. Kumar, S. Devari and B. A. Shah, Chem. Commun., 2014, 50, 9533-9535. 